\title{
Transmittance of Near Infrared Energy by Binary Glasses ${ }^{12}$
}

\section{By Jack M. Florence, Francis W. Glaze, Clarence H. Hahner, and Ralph Stair}

\begin{abstract}
A study has been made of the transmittance of near infrared energy by a number of binary glasses. Of the systems studied, the lithia-silica and lead oxide-silica were found to have the highest transmittance of energy in the range of wavelengths from 3.0 to 5.0 microns. The transmittance of lithia-silica is compared with that of the other alkali-silica glasses. Values of transmittance are given for lead silicate glasses of higher lead content than have been previously reported in the literature.
\end{abstract}

\section{Introduction}

Published data concerning the relation between the transmittance of infrared energy and the composition of glasses have been limited to a relatively few investigations. A compilation of these investigations is given by Eitel, Pirani, and Scheel [1] ${ }^{3}$ in Glastechnische Tabellen, which was published in 1932. Since that date, Gerlovin [2] has published a study of borate, silicate, and phosphate glasses; a study of glasses incorporating rare earth and other oxides has been published by Stair and Faick [3]. The majority of these studies are concerned with the absorption bands of complex glasses. In this paper only data on experimental binary glasses are considered.

\section{Preparation of the Glasses}

The glasses that were made for this work were melted in platinum crucibles of $150-$ to $300-\mathrm{g}$ eapacity. The batch materials used were of the highest commercial purity as used in the manufacture of optical glass, and no special processes were used to purify the materials before use. The only heavy metal that was present as an impurity in sufficient quantities to have any possible effect on the transmittance was iron. The following quan-

\footnotetext{
1 Made possible by a transfer of funds from the Department of the Navy, Bureau of Ships, to the National Bureau of Standards.

${ }_{2}$ This paper will also appear in the December issue of the Journal of the American Ceramic Society.

${ }^{3}$ Figures in brackets indicate the literature references at the end of this paper.
}

tities as $\mathrm{Fe}_{2} \mathrm{O}_{3}$ were present in the batch materials used :

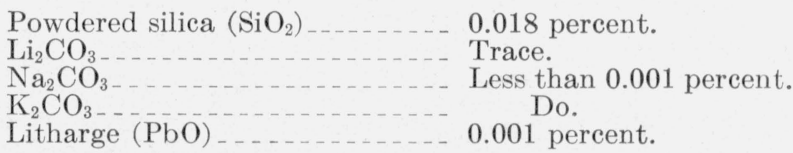

The glasses were melted and fined in a platinum resistance furnace in about $6 \mathrm{hr}$ and then poured into a mold to form a sample about $1 / 4$ in. thick. The samples were of a quality equivalent to that of optical glass. Samples were prepared for measurement by grinding and polishing into plates having plane parallel faces $1 \mathrm{in}$. square.

\section{Composition of the Glasses}

Measurements were made on glasses of lithium silicate, sodium silicate, potassium silicate, and lead silicate. The lithium silicate glass had a composition close to that of lithium metasilicate $\left(\mathrm{Li}_{2} \mathrm{O} .2 \mathrm{SiO}_{2}\right)$. Compositions appreciably different from this ratio could not be cooled without devitrification [4]. The sodium silicate glasses contained $21.28,24.79$, and 31.02 mole percent of $\mathrm{Na}_{2} \mathrm{O}$. The potassium silicate glass contained 20.35 mole percent of $\mathrm{K}_{2} \mathrm{O}$. These glasses, listed in table 1 , are within such ranges of compositions that comparisons may be made by mole-percentage and weight-percentage compositions within 3 percent. A stable $\mathrm{K}_{2} \mathrm{O}-\mathrm{SiO}_{2}$ glass of 32.41 mole percent of $\mathrm{K}_{2} \mathrm{O}$ could not be made for direct comparison with the $\mathrm{Li}_{2} \mathrm{O}$ glass. The lead silicate 
glasses made contained 70.86, 79.91, and 88.08 weight percent of $\mathrm{PbO}$. Potassium and lead silicate [5] glasses beyond these ranges, either could not be melted and cooled without difficulty or were not sufficiently resistant to moisture so that a polished sample could be made for transmission measurements. The compositions of these glasses, by chemical analysis, are given in table 1 .

Table 1. Glass compositions

\begin{tabular}{|c|c|c|c|c|c|c|c|c|c|c|c|c|}
\hline Glass No. & \multicolumn{2}{|c|}{$\mathrm{SiO}_{2}$} & \multicolumn{2}{|c|}{$\mathrm{Li}_{2} \mathrm{O}$} & \multicolumn{2}{|c|}{$\mathrm{Na}_{2} \mathrm{O}$} & \multicolumn{2}{|c|}{$\mathrm{K}_{2} \mathrm{O}$} & \multicolumn{2}{|c|}{$\mathrm{PbO}$} & \multicolumn{2}{|c|}{$\mathrm{Fe}_{2} \mathrm{O}_{3}$} \\
\hline & Weight & $\begin{array}{c}\text { Mole } \\
\text { percent }\end{array}$ & $\begin{array}{l}\text { Weight } \\
\text { percent }\end{array}$ & $\begin{array}{c}\text { Mole } \\
\text { percent }\end{array}$ & $\begin{array}{l}\text { Weight } \\
\text { percent }\end{array}$ & $\begin{array}{c}\text { Mole } \\
\text { percent }\end{array}$ & $\begin{array}{l}\text { Weight } \\
\text { percent }\end{array}$ & $\begin{array}{c}\text { Mole } \\
\text { percent }\end{array}$ & $\begin{array}{l}\text { Weight } \\
\text { percent }\end{array}$ & $\begin{array}{c}\text { Mole } \\
\text { percent }\end{array}$ & $\begin{array}{l}\text { Weight } \\
\text { percent }\end{array}$ & $\begin{array}{c}\text { Mole } \\
\text { percent }\end{array}$ \\
\hline 1 & $\begin{array}{l}80.72 \\
78.01\end{array}$ & $\begin{array}{l}67.58 \\
78.71\end{array}$ & 19. 26 & 32.41 & 91 & 8) & -.... & ..... & ...... & -..... & 0.017 & 0.005 \\
\hline $3 \ldots$ & 74.60 & 75. 21 & ........ & ......... & $\begin{array}{l}21.98 \\
25.38\end{array}$ & $\begin{array}{l}21.20 \\
24.79\end{array}$ & -..... & ........ & .......... & ........ & $\begin{array}{r}.015 \\
.015\end{array}$ & $\begin{array}{l}.000 \\
.006\end{array}$ \\
\hline $4 \ldots$ & 68. 29 & 68.97 & -.... & - . & 31.70 & 31.02 & ..... & . . . & ...... & & .014 & .006 \\
\hline $5 \ldots$ & 71.37 & 79.64 & - & - . & -.... & -... & 28.61 & 20.35 & .... & - & .016 & .007 \\
\hline 6. & 29.13 & 60.44 & - . - & - & ..... & -.... & - & & 70.86 & 39.55 & .009 & .01 \\
\hline $7 \ldots$ & 20.08 & 48. 28 & ...... & ...... & ..... & ..... & - . & ...... & 79.91 & 51.70 & .008 & .01 \\
\hline $8 \ldots$ & 11.91 & 33.44 & $\ldots$ & - n... & $\ldots$ & ..... & - & -... & 88.08 & 66.54 & .007 & .02 \\
\hline
\end{tabular}

\section{Near Infrared Transmittances}

The infrared spectra of glasses have wide regions of absorption and transparency. The transmittance for glasses of the same batch composition will vary with the thickness of the sample and the presence in the glass of small amounts of impurities, among which are iron and nickel oxides and water vapor [6].

The spectral transmissions were determined radiometrically by means of a fluorite prism mirror spectrometer, Nernst glower, and a vacuum thermopile. A detailed description of the method is given in previous publications $[7,8,9,10,11$, and 12]. These data are given in figures 1 to 5 without correction for reflectance.

The simplest glass from the standpoint of chemical composition, though not ease of preparation, is fused silica. The transmission curve for transparent fused silica (fig. 1) indicates a high transmittance to about $3.5 \mu$. The absorption band at $2.8 \mu$ is characteristic of silicate glasses, but it is a minimum in fused silica. Two additional absorption bands are present at the wavelengths of 3.7 and $4.45 \mu$. The thickness of the sample was $2.85 \mathrm{~mm}$.

\section{Transmittances of the Alkali-Silica Glasses}

The transmittances of a representative lithium silicate glass 1 are shown in figure 2 for a sample $5.74 \mathrm{~mm}$ thick. This thickness of sample gives a good contrast for the range of wavelengths from 3.0 to $5.0 \mu$. In figure 3 the transmission

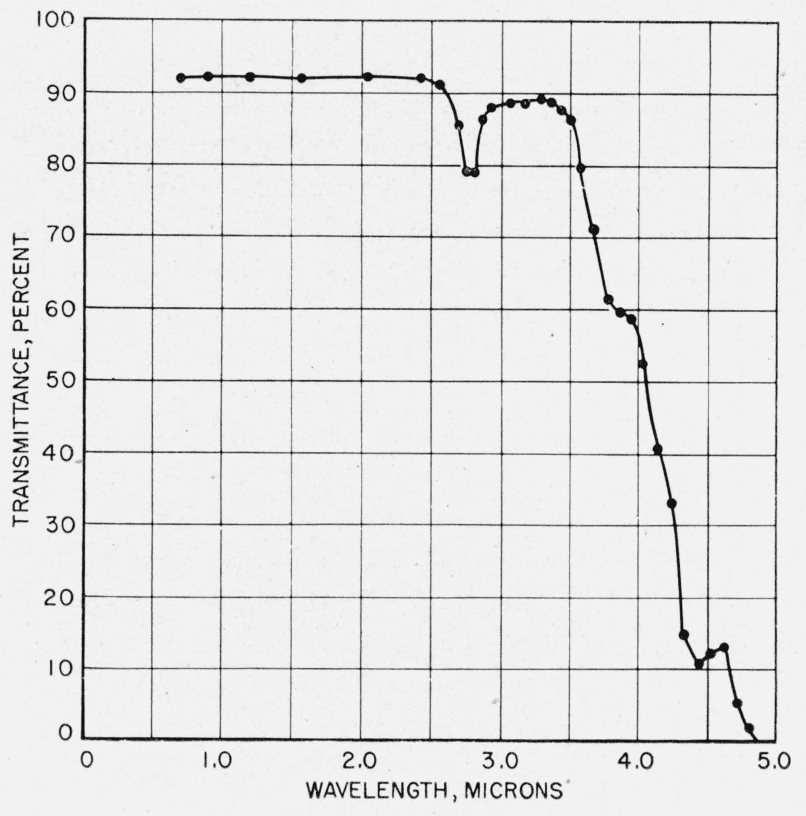

FIGURE 1. Transmittance of infrared energy by fused silica. Thickness of sample $=2.85 \mathrm{~mm}$.

curves of the sodium silicate glasses 2,3 , and 4 are shown. The highest transmittance is shown by glass 3 , which is near the composition of the eutectic reported by Kracek [13] for the $\mathrm{Na}_{2} \mathrm{O}-\mathrm{SiO}_{2}$ system. A comparison of the transmittance of the lithium silicate glass 1 with that of the sodium silicate glasses 2,3 , and 4 , shows that the lithium silicate glass has a higher transmittance of infrared energy than any of the sodium silicate glasses. The potassium silicate glass 5 is similar 


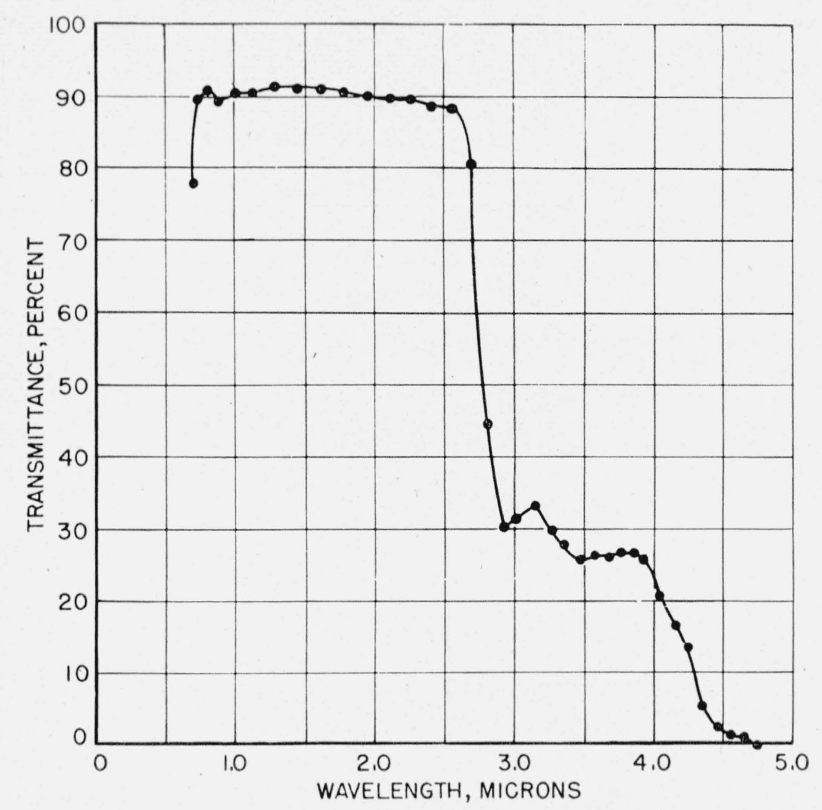

FigurE 2. Transmittance of infrared energy by a lithium silicate experimental glass.

Thickness of glass $1=5.74 \mathrm{~mm}$.

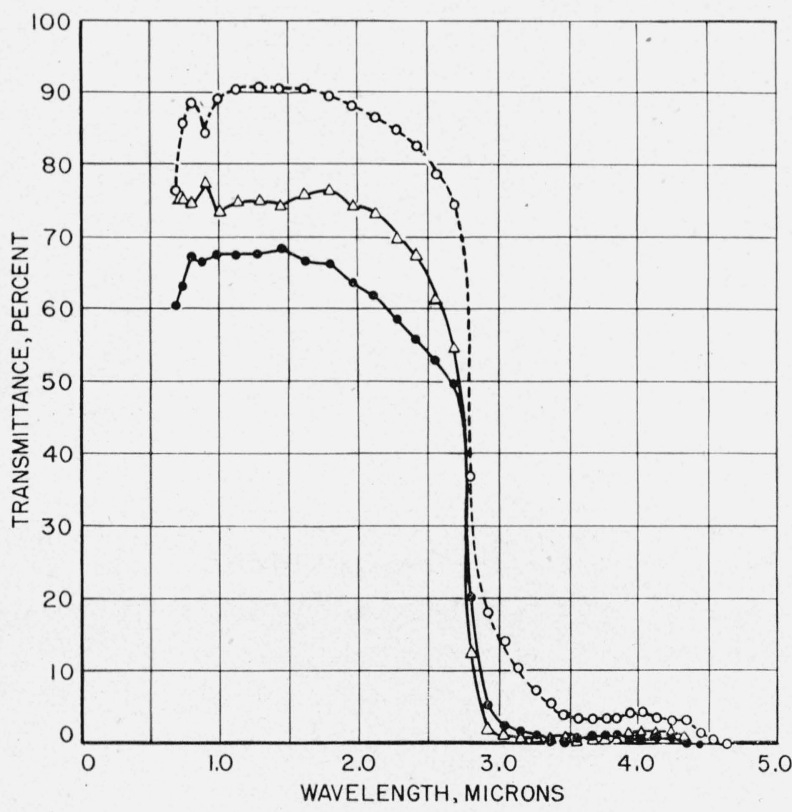

FIgure 3. Transmittance of infrared energy by sodium silicate experimental glasses.

Thickness of glass $2=6.21 \mathrm{~mm}$; glass $3=4.84 \mathrm{~mm}$; and glass $4=4.67 \mathrm{~mm}$ - Glass $2 ; \bigcirc$, glass $3 ; \triangle$, glass 4 .

to the sodium silicate glasses in the transmittance of infrared energy, as shown in figure 4. Potassium silicate glass 5 is equivalent to the sodium silicate glass 2 on a mole percentage basis.

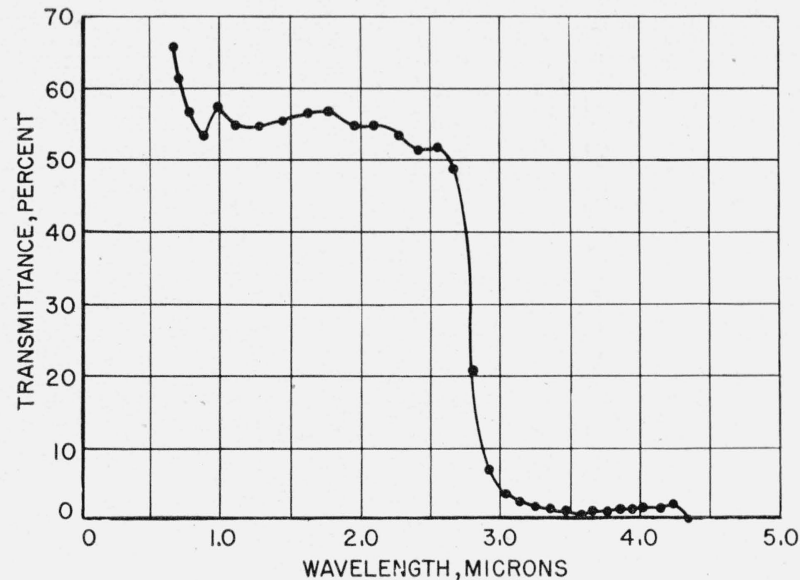

FIGURE 4. Transmittance of infrared energy by potassium silicate glass.

Thickness of glass $5=4.45 \mathrm{~mm}$.

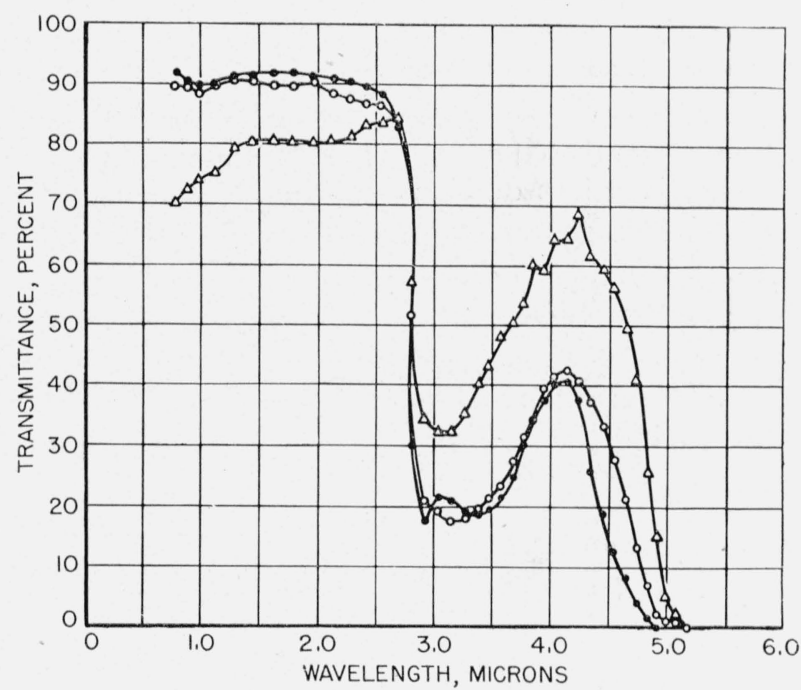

Figure 5. Transmittance of infrared energy by lead silicate glasses.

Thickness of glass $6=3.00 \mathrm{~mm}$; glass $7=3.21 \mathrm{~mm}$; and glass $8=2.81 \mathrm{~mm}$. - Glass $6 ; \bigcirc$, glass $7 ; \triangle$, glass 8 .

\section{Transmittances of Lead-Silica Glasses}

Gerlovin [2] stated that the greatest transmittance in the infrared spectrum is shown by the glasses in the silicate systems and, among the silicate systems, by the lead silicates. It was also shown that for wavelengths from 4 to $5 \mu$, lead silicate glasses have a higher transmittance than fused silica glass. His report gave the transmittance curve of a lead silicate glass having the composition $4 \mathrm{PbO} .6 \mathrm{SiO}_{2}$ (71\% of lead oxide, $29 \%$ of silica, by weight). 
The experimental glasses prepared for our work contained 70.86 to 88.08 percent by weight of lead oxide. The transmittance curve for glass 6 shown, in figure 5 , is similar to that published by Gerlovin. Glasses 7 and 8 contain more lead oxide than any glass reported by Gerlovin. It is evident that increasing the lead oxide content above 70.86 percent decreases the percentage of transmittance up to the $2.8-\mu$ absorption band, but increases the transmittance for wavelengths from 3.25 to about $5.0 \mu$.

\section{Summary}

The transmittance of infrared energy by lithium, sodium, potassium, and lead silicate glasses has been measured for wavelengths of 0.7 to $5 \mu$. It was found that glasses containing lithia-silica gave a greater transmittance of infrared energy than the glasses of either soda-silica or potashsilica systems.

Increasing the percentage of lead oxide in a lead silicate glass does not increase the transmittance of infrared energy for all wavelengths.

A glass of the composition 71 percent of $\mathrm{PbO}$, 29 percent of $\mathrm{SiO}_{2}$, will give the maximum transmittance of infrared energy in the range of wavelengths from 0.8 to about $2.7 \mu$.

Increasing the quantity of lead oxide above 71 percent increases the transmittance of infrared energy in the range of wavelengths from 3.25 to about $5.0 \mu$, but lowers the transmittance in the range from 0.8 to $2.7 \mu$.

The authors thank Mrs. Helen Pool and J. J. Diamond for their cooperation in making the measurements of transmittances and the chemical analyses, respectively.

\section{References}

[1] W. Eitel, M. Pirani, and K. Scheel, Glastechnische tabellen (29 Ultrarotdurchläss, Springer, Berlin, 1932).

[2] J. I. Gerlovin, Acad. Sci. URSS 38, 5 to 6, 170 (1943).

[3] R. Stair and C. A. Faick, J. Research NBS 38, 95 (1947) RP1761.

[4] F. C. Kracek, J. Phys. Chem. 34, 264 (1930).

[5] R. F. Geller, A. S. Creamer, and E. N. Bunting, J. Research NBS 13, 237 (1934) RP705.

[6] A. J. Harrison, J. Am. Ceram. Soc. 30, 362 (1947).

[7] R. Stair and W. W. Coblentz, BS J. Research 11, 703 (1933) RP617.

[8] W. W. Coblentz, BS Bul. 10, 1 (1913) S204.

[9] W. W. Coblentz, BS Bul. 13, 423 (1916) S282.

[10] W. W. Coblentz, BS Sci. Pap. 1\%, 187 (1921) S413.

[11] W. W. Coblentz, BS Sci. Pap. 1\%, 187 (1921) S413.

[12] R. Stair and W. W. Coblentz, J. Research NBS 15. 295 (1935) RP830.

[13] F. C. Kracek, J. Phys. Chem. 34, 1583 (1930).

Washington, August 16, 1948. 